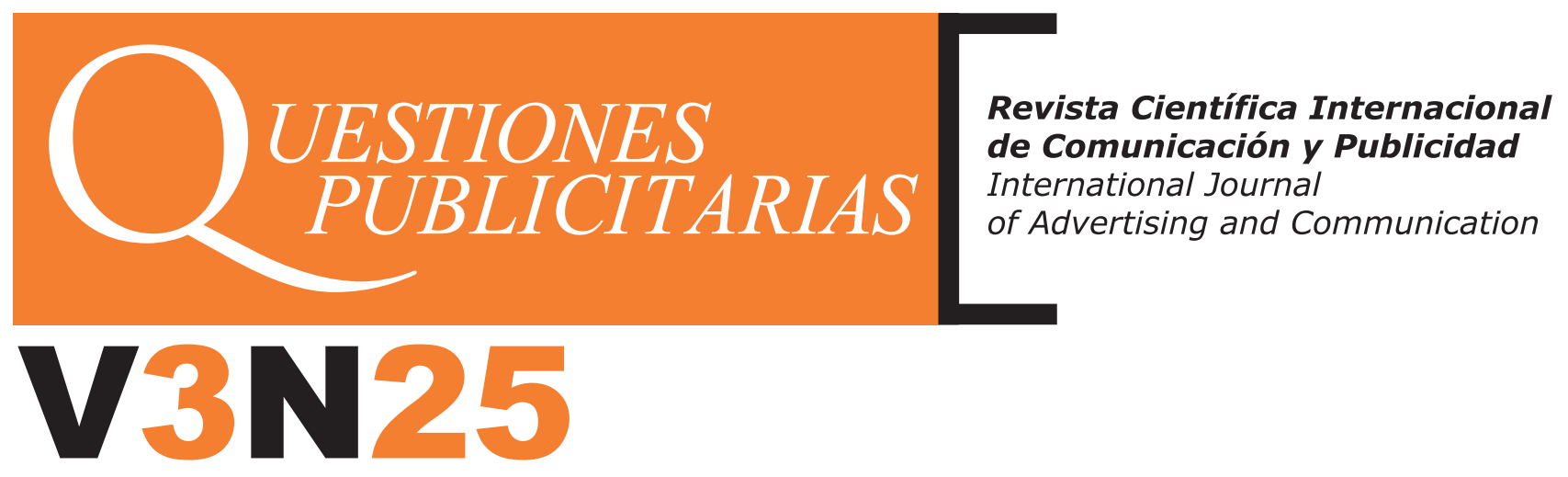

\title{
Experimenta punto es Experimenta dot es
}

Daniel Tena-Parera. Universitat Autònoma de Barcelona; daniel.tena@uab.cat

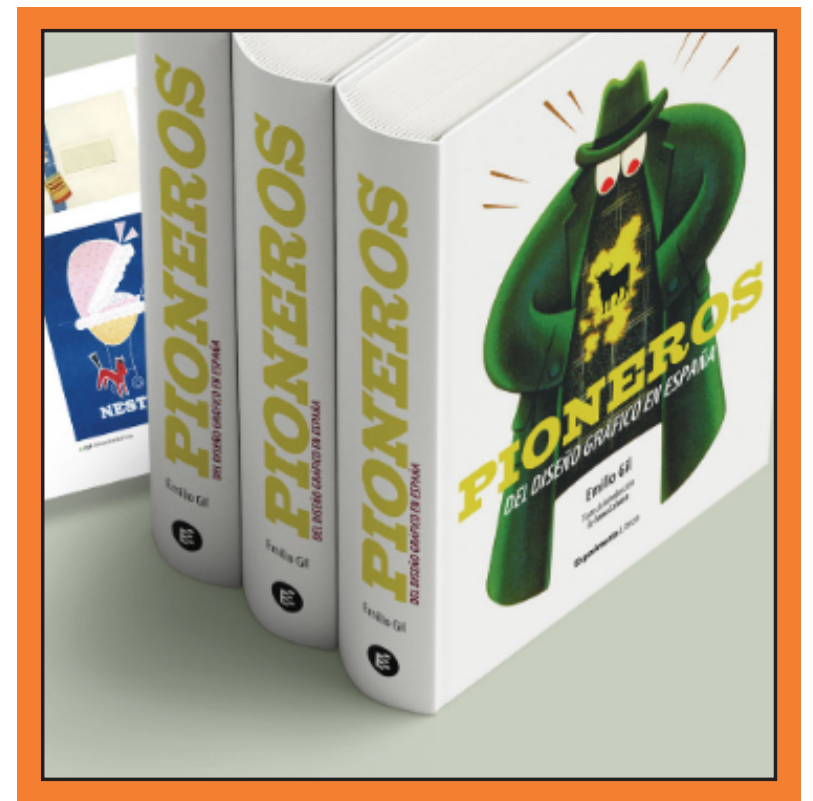

\section{Resumen}

En setiembre de 2019 pudimos conocer de primera mano, la revitalización de la Editorial Experimenta. Ésta, que había nacido en Madrid en el año 1988 con el objeto de impulsar la cultura del proyecto en España, durante los años de la crisis económica tuvo dificultades para seguir con su labor. Ahora, con la filosofía y visión altruista de sus mecenas, se retoma y dinamiza el proyecto editorial con el objetivo de proporcionar los mejores títulos sobre diseño que se han publicado y para la publicación de contenidos actuales.

\section{Palabras clave}

Publicidad; creatividad; diseño; editorial Experimenta.

\begin{abstract}
In September 2019 we were able to see first-hand, the revitalization of Editorial Experimenta. This, which was born in Madrid in 1988 with the aim of promoting the culture of the project in Spain, during the years of the economic crisis, had difficulties to continue with its work. Now, with the philosophy and altruistic vision of its patrons, the editorial project is revitalized in order to provide the best titles on design that have been published and for the publication of current content.
\end{abstract}

\section{Keywords}

Advertising; creativity; design; editorial Experimenta.

(Octubre, 2019). Editorial Experimenta. Recuperado de https://www.experimenta.es/editorial-experimenta/.

\section{RESENA pp. 27-29}

como citar este artículo/referencia normalizada

Tena Parera, Daniel (2020) “Experimenta punto es”. Questiones Publicitarias, 25, pp. 27-29 
Era el año 1988 cuando se creó en Madrid la editorial Experimenta con la intención de editar libros sobre diseño, arquitectura y comunicación visual e impulsar la cultura del diseño en España. Su catálogo está repleto de contenidos con un carácter eminentemente vinculados con la estética y orientados hacia ella. Cierto es que era una editorial de pequeñas dimensiones pero con grandes propósitos. Con el tiempo se transformó en referencia necesaria para testimoniar obras, autores y contenidos sobre el diseño.

La editorial Experimenta, responsable además de una publicación periódica se ha convertido en toda una referencia internacional. Después de algunas dudas y de una cierta inactividad, actualmente, la recuperada Experimenta publica una revista con difusión en más de cincuenta países. Además, con su portal online se ofrece a los profesionales del diseño, la arquitectura y la comunicación.

Así Experimenta, con una renovada plataforma especializada en diseño gráfico, diseño industrial, la arquitectura, la tecnología y la comunicación visual sigue firme con lo que empezó hace más de 3 décadas.

Animamos a los lectores de este texto a indagar sobre su catalogo editorial. En Experimenta.com se puede encontrar la colección "Experimenta Theoria", que es una línea de libros que incorpora títulos y autores representativos del diseño, la "Guía del Diseño Español", la "Guía del Hábitat" y la "Guía del Diseño Gráfico y la Comunicación Visual". Todas estas colecciones van a permitirnos descubrir o redescubrir la riqueza del mundo del diseño y una nueva oportunidad para establecer una cultura común del diseño en las relaciones entre la industria, los diseñadores y el mercado. 
Daniel Tena

REFERENCIAS BIBLIOGRÁFICAS

https://www.experimenta.es/; consulta en octubre de 2019 
